Florida International University

From the SelectedWorks of Sheldon D. Fields

August, 2011

Age of MSM sexual debut and risk factors: results from a multisite study of racial/ethnic minority YMSM living with HIV

Sheldon Fields, Florida International University

Available at: https://works.bepress.com/sheldon_fields/4/ 


\title{
Age of MSM Sexual Debut and Risk Factors: Results from a Multisite Study of Racial/Ethnic Minority YMSM Living with HIV
}

\author{
Angulique Y. Outlaw, Ph.D., ${ }^{1}$ Gregory Phillips II, M.S., ${ }^{2}$ Lisa B. Hightow-Weidman, M.D., M.P.H., ${ }^{3}$ \\ Sheldon D. Fields, Ph.D., R.N., ${ }^{4}$ Julia Hidalgo, Sc.D., M.S.W., M.P.H., ${ }^{2}$ Bonnie Halpern-Felsher, Ph.D., ${ }^{5}$ \\ Monique Green-Jones, M.P.H.,, and The Young MSM of Color SPNS Initiative Study Group
}

\begin{abstract}
The average reported age of sexual debut for youth in the United States is 14.4 years, with approximately 7\% reporting their sexual debut prior to age 13. While the research literature on sexual debut for youth addresses gender and ethnic differences (with males and African-American youth experiencing earlier sexual debut), there is limited data regarding factors associated with sexual debut for young men who have sex with men (YMSM). Early sexual debut poses potential health risks, such as contracting HIV with an increased risk of unprotected intercourse. Given current high HIV infection rates for racial/ethnic minority YMSM, learning more about their sexual debuts and associated risk factors of this population is of great importance. This study investigated risk behaviors and emotional distress, and their association with MSM sexual debut for a multisite cohort of racial/ethnic minority YMSM living with HIV. We hypothesized that a MSM sexual debut younger than age 16 would be associated with engagement in more high-risk sexual behaviors (unprotected sex and exchange sex), substance use, and emotional distress than a MSM sexual debut at age 16 or older. Results indicated that participants having a MSM sexual debut before the age of 16 reported more exchange sex; drug use (specifically marijuana); emotional/psychological problems related to substance use; and a history of suicide attempts, compared to participants with later MSM sexual debuts. Comprehensive interventions that are racially/ethnically sensitive, inquire about initial sexual experiences, and focus on sexual health and healthy relationships are needed to improve health outcomes for this population.
\end{abstract}

\section{Introduction}

A CCORding to the Centers for Disease Control and Prevention's latest statistics, the largest number of new HIV infections among minority young men who have sex with men (YMSM) occurred in the 13- to 29-year-old age group. ${ }^{1}$ Additionally, the Young Men's Survey, a multisite HIV prevalence study, revealed that HIV prevalence rate among racial/ethnic minority YMSM aged 15-22 was much higher than among similar aged White MSM. African-American YMSM had a much higher prevalence $(14.1 \%)$ of testing positive for HIV than Hispanic YMSM (6.9\%) or White YMSM
$(3.3 \%)$. In this and other studies, racial/ethnic minority YMSM had the highest rate of undiagnosed HIV infection. ${ }^{2-4}$ Despite high HIV prevalence rates among racial/ethnic minority YMSM, there is a relative paucity of data on the risk behaviors of this group, and additional research is needed given that unprotected anal intercourse does not appear to account for the disparity in prevalence rates. ${ }^{5-8}$ Such information is critical to strengthen prevention and intervention efforts aimed at decreasing HIV acquisition within this highrisk population.

Moreover, to prevent further transmission, ongoing risky sexual behaviors among racial/ethnic minority YMSM living

\footnotetext{
${ }^{1}$ Wayne State University, Horizons Project, Detroit, Michigan.

${ }^{2}$ The George Washington University School of Public Health and Health Services, Washington, District of Columbia.

${ }^{3}$ University of North Carolina, Chapel Hill, Chapel Hill, North Carolina.

${ }^{4}$ MOCHA Center, Inc., University of Rochester, Rochester, New York.

${ }^{5}$ University of San Francisco, San Francisco, California.

This study was supported by a grant from the U.S. Department of Health and Human Services, Health Resources and Services Administration. Responsibility for the content of this report rests solely with the authors.
} 
with HIV need to be understood and addressed. However, the research literature focusing on this population tends to focus on youth in general living with HIV rather than specific subpopulations such as YMSM. Youth living with HIV report a higher prevalence of high-risk sexual behaviors than uninfected youth in the United States (US).$^{9-13}$ Substance use is prevalent among youth living with HIV, thus increasing the potential risk of HIV transmission. ${ }^{19-12}$ Moreover, emotional distress has been found to be associated with substance use and subsequent engagement in high-risk sexual behavior in HIV-positive males. ${ }^{14,15}$

Exchange sex (i.e., sex in exchange for money, drugs, or other needs) has also been associated with increased risk for acquisition of HIV and sexually transmitted diseases (STDs) among both HIV-positive and HIV negative youth. ${ }^{16,17}$ Edwards and colleagues investigated exchange sex and associated characteristics for a representative sample of youth $\left(7^{\text {th }}-12^{\text {th }}\right.$ grade). ${ }^{16}$ They found that almost $4 \%$ of the youth reported having exchanged sex for drugs or money. Two-thirds of the participants engaging in exchange sex were males, and the odds for having engaged in exchange sex were higher for African-American youth $(\mathrm{OR}=2.17 ; \mathrm{CI}=1.67-2.82)$. Youth who had a history of exchange sex were also more likely to be HIVpositive than youth with no history of exchange sex. ${ }^{16}$

The first sexual experience is a normal part of human development. Almost 70\% of all high school youth experience their sexual debut (defined as vaginal sex) by age $18 .{ }^{18-20}$ The average reported age of sexual debut for youth in the United States is 14.4 years, with approximately $7 \%$ reporting their sexual debut prior to age 13. More male than female youth report an early sexual debut (before the age of 13), and African-American youth tend to experience their sexual debut earlier than other racial/ethnic groups. ${ }^{19,21}$ An early sexual debut poses significant health risks, including engagement in unprotected intercourse, unintended pregnancy, ${ }^{22-24}$ and an increased risk of contracting STDs and HIV. ${ }^{25}$ While the research literature focusing on the early sexual debuts for youth has addressed gender and ethnic differences, there is little information regarding the early sexual debuts for racial/ ethnic minority YMSM.

Information about the associations among risk behaviors (high-risk sexual behavior and substance use) and risk factors (emotional distress), and MSM sexual debut may provide insight into behavior patterns for racial/ethnic minority YMSM living with HIV. Moreover, examining the age at MSM sexual debut and associated risk factors for racial/ethnic minority YMSM living with HIV is important to maximize health outcomes and intervention efforts. This study investigated current high-risk sexual behavior, substance use, and emotional distress to determine their association with the age at MSM sexual debut for a multisite cohort of racial/ethnic minority YMSM living with HIV. We hypothesized that youth with a MSM sexual debut younger than the age of 16 would report more high-risk sexual behavior (unprotected sex and exchange sex), substance use, and emotional distress than youth with a MSM sexual debut at age 16 or older.

\section{Methods}

\section{Participants}

Participants for this study were enrolled in a larger multisite study at one of eight Special Projects of National Sig- nificance (SPNS) funded demonstration sites (Bronx, NY; Chapel Hill, NC; Chicago, IL; Detroit, MI; Houston, TX; Los Angeles, CA; Oakland, CA; and Rochester, NY). As part of the larger evaluation, each study site had its own outreach, linkage, and retention strategies. Study sites operated independently, and interventions varied based on local program design. Eligibility criteria included: (1) born male, (2) HIV seropositive and not currently in care, (3) self-reported sex with males or intent to have sex with males, (4) self-identified as non-white, (5) between 13- and 24-years-old at the time of the baseline interview, and (6) able to provide written informed consent or assent. The overall sample size for study was 363, although only 342 participants reported age at MSM debut.

\section{Procedure}

All eligible participants provided either written informed consent or assent to participate in the study and were administered a standardized face-to-face interview by experienced interviewers at each of the sites at baseline and every 3 months thereafter. Only baseline data were utilized for these analyses. Data were collected between June 1, 2006 and August 31, 2009. Participants received compensation (amounts specific to and determined by each study site) for their time. Data collected from all eight sites were entered into a secure web-based data entry portal maintained by an evaluation center at The George Washington University. All instruments and protocols were approved by SPNS staff of the HIV / AIDS Bureau, Health Resources and Services Administration; local Institutional Review Boards (IRBs) at each of the eight study sites; and The George Washington University IRB.

\section{Measures}

The interview questionnaire was adapted from standardized tools used in previous studies, including the Young Men's Survey, the Youth Risk Behavior Survey, National HIV Behavioral Surveillance tools, the HIV Cost and Service Utilization Study, previous SPNS multi-site evaluations, Adolescent Medicine Trials Network for HIV / AIDS Interventions, and the Center for Epidemiologic Studies.

\section{Age at MSM sexual debut}

Age at MSM sexual debut was dichotomized to "less than age 16 " and "equal to or greater than age 16 " for analyses. This dichotomy was based on the research literature dealing with early versus late sexual debuts of youth in the United States. ${ }^{10,26}$

\section{Demographics}

Participants reported age, race/ethnicity, sexual orientation, education, and employment.

\section{Risk factors}

High-risk sexual behavior. Participants were asked about the types of sexual behavior (oral, anal, and vaginal) they engaged in and the gender of their partners (male and female) over the last 3 months. Participants were also asked about exchanging sex for money, food, housing, drugs, transportation, or to avoid, physical or emotional abuse. 
Substance use. Participants were asked about the number of days they used alcohol in the past 2 weeks. Youth were also asked about the use of various other drugs (e.g., marijuana, cocaine, amphetamines, painkillers) in the past 3 months, and whether the use of such drugs led to any emotional difficulties (e.g., depression, paranoia, strange ideas).

Emotional distress. Participants completed the Center for Epidemiologic Studies Depression Scale (CES-D). ${ }^{27}$ This 20item measure provides a depression quotient by measuring depressive feeling and behaviors during the past week. Items (e.g., restless sleep, feeling fearful, feeling lonely) are rated " $<1$ day = rarely or none of the time"; "1-2 days= some or little of the time"; "3-4 days=occasionally or moderate amount of time"; and "5-7 days = most or all of the time." Scores range from 0 to 60 , with a score of 16 or greater indicating significant depression symptomology. Participants were also asked if they experienced a period of feeling sad, blue, and unhappy for at least 1 week in the past 3 months. Finally, participants were asked about a history of suicide attempts.

\section{Data analyses}

Statistical analyses were performed using SAS v.9.1 (SAS Institute, Cary, NC). Prior to analyses, assumptions of normality and linearity were evaluated and screening was conducted for outliers. No outliers or significant skewness was detected, and therefore the variables were left untransformed. Univariable frequency distributions and means with standard deviations were used to describe categorical and continuous variables, respectively. Pearson's Chi-square analyses were conducted to determine whether differences on outcome variable were significant.

\section{Results}

\section{Descriptive statistics}

Table 1 shows participant characteristics at baseline. Age of participants ranged from 15 to 24 years $($ mean $=20.4 ; \mathrm{SD}=1.9$ ). Only 1 participant was less than age 16 at the time of study enrollment. Approximately three-quarters (67\%) of the youth were African-American, and 21\% were Latino. Sixty-four percent self-identified as gay or homosexual, $20 \%$ as bisexual, and $13 \%$ as another individualized identity (e.g., multiple identities such as "I'm me," "God's child"). Almost threequarters $(71 \%)$ of participants had at least a high school education, and $43 \%$ had attended college.

The mean self-reported age at MSM sexual debut was 14.5 years $(S D=3.2)$. Approximately half of the participants had a MSM sexual debut of less than age $16(n=184,54 \%)$. Nineteen percent of participants $(n=64)$ had a MSM sexual debut before the age of 13 . The mean self-reported age at heterosexual debut was $14.1(\mathrm{SD}=2.7)$, and mean age at HIV seropositive diagnosis was $19.9(\mathrm{SD}=2.2)$.

Table 2 shows reported risk behaviors (i.e., high-risk sexual behavior, substance use, and emotional distress) for the sample at baseline. Sixty-eight percent of participants reported engaging in insertive oral sex without a condom in the past 3 months, while $67 \%$ reported receptive oral sex without a condom for the same period. Twenty-six percent of participants reported engaging in unprotected insertive anal sex in the past 3 months, while $31 \%$ reported unprotected receptive
Table 1. Characteristics for a Multisite Cohort of Racial/Ethnic MinoRity YMSM Living WITH HIV $(N=363)$

\begin{tabular}{|c|c|}
\hline & Mean (SD); range \\
\hline \multicolumn{2}{|l|}{ Age } \\
\hline Overall sample & 20.4 (1.9); 15-24 \\
\hline MSM sexual debut & 14.5 (3.2); 4-21 \\
\hline Heterosexual debut & 14.1 (2.7); 5-22 \\
\hline HIV diagnosis & $\begin{array}{l}19.9(2.2) ; 9-25 \\
\quad N(\%)\end{array}$ \\
\hline \multicolumn{2}{|r|}{ 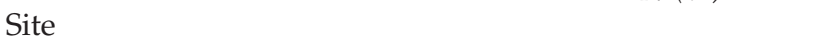 } \\
\hline Oakland, CA & $29(8)$ \\
\hline Bronx, NY & $58(16)$ \\
\hline Houston, TX & $50(14)$ \\
\hline Los Angeles, CA & $65(18)$ \\
\hline Rochester, NY & $8(2)$ \\
\hline Chapel Hill, NC & $81(22)$ \\
\hline Detroit, MI & $50(14)$ \\
\hline Chicago, IL & $22(6)$ \\
\hline \multicolumn{2}{|l|}{ Race/ethnicity } \\
\hline African-American & $242(67)$ \\
\hline Latino & $78(21)$ \\
\hline Multiracial $^{\mathrm{a}}$ & $43(12)$ \\
\hline \multicolumn{2}{|l|}{ Sexual orientation } \\
\hline Gay/homosexual & $231(64)$ \\
\hline Bisexual & $72(20)$ \\
\hline Heterosexual & $10(3)$ \\
\hline Other $^{\mathrm{b}}$ & $48(13)$ \\
\hline \multicolumn{2}{|l|}{ Education } \\
\hline Less than high school degree & $105(29)$ \\
\hline High school degree/GED & $101(28)$ \\
\hline Some college & $157(43)$ \\
\hline Currently employed & $162(46)$ \\
\hline
\end{tabular}

${ }^{\mathrm{a}}$ Multiracial $=$ African-American and Caucasian, African-American and Latino, African-American and Native American, and three or more race/ethnicities; ${ }^{\mathrm{b}}$ Other $=$ two-spirited, bi-special, queer, trisexual, multiple identities, I'm me, and God's child.

anal sex. Although 23\% of participants self-identified as bisexual or heterosexual, only $5 \%(n=15)$ reported engaging in vaginal sex in the past 3 months, and $20 \%$ did not use a condom at their last sexual encounter with a woman. Thirteen percent of participants $(n=48)$ reported engaging in exchange sex (69\% exchanged sex for money).

Forty-seven percent of participants reported drinking alcohol in the past 2 weeks (mean $=1.8$ days; $\mathrm{SD}=2.8$; range $=0-14$ days). Seventy-four percent had used drugs in the past 3 months, with the most commonly used drugs being marijuana $(62 \%)$, painkillers $(18 \%)$, amphetamines $(12 \%)$, sedatives (12\%), and cocaine (11\%). Eighteen percent of participants reported experiencing emotional/psychological problems due to drug and/or alcohol use in the past 3 months. More than half of participants (52\%) reported significant depressive symptomology during the past week (CES-D $\geq 16$ ), with $56 \%$ reported a period of at least a week of feeling sad, blue, and unhappy in the past 3 months. Twentythree percent reported ever trying to commit suicide (Table 2).

\section{Group comparisons}

Comparisons of baseline characteristics by age at MSM sexual debut (less than age 16 years versus age 16 years or 
Table 2. Risk Factors for a Multisite Cohort of RACIAL/ETHNic MinORITY YMSM LiVING WITH HIV

\begin{tabular}{|c|c|}
\hline & $\mathrm{N}(\%)$ \\
\hline \multicolumn{2}{|c|}{ Sexual behavior without a condom, past 3 months } \\
\hline Insertive oral sex & $142(68)$ \\
\hline Receptive oral sex & $134(67)$ \\
\hline Insertive anal sex & $39(26)$ \\
\hline Receptive anal sex & $59(31)$ \\
\hline Vaginal sex & $3(20)$ \\
\hline Anal sex with women & $1(25)$ \\
\hline Exchange sex, ${ }^{\text {a }}$ past 3 months & $48(13)$ \\
\hline Drank alcohol, past 2 weeks & $121(47)$ \\
\hline \multicolumn{2}{|l|}{ Used drugs, past 3 months } \\
\hline Any drugs & $200(74)$ \\
\hline Marijuana & $173(62)$ \\
\hline Cocaine & $24(11)$ \\
\hline Sedatives & $27(12)$ \\
\hline Amphetamines & $27(12)$ \\
\hline Painkillers & $40(18)$ \\
\hline Inhalants & $22(10)$ \\
\hline LSD & $17(8)$ \\
\hline Heroin & $1(1)$ \\
\hline $\begin{array}{l}\text { Emotional/psychological problems from } \\
\text { using drugs or alcohol, past } 3 \text { months }\end{array}$ & $60(18)$ \\
\hline \multicolumn{2}{|l|}{ CES-D } \\
\hline$<16$ & $160(48)$ \\
\hline$\geq 16$ & $176(52)$ \\
\hline $\begin{array}{l}\text { Period of at least a week of feeling sad, } \\
\text { blue, and unhappy, past } 3 \text { months }\end{array}$ & $76(56)$ \\
\hline Tried to take own life & $79(23)$ \\
\hline
\end{tabular}

${ }^{\mathrm{a} E x c h a n g e ~ s e x}=$ money, food, housing, drugs, transportation, and avoidance of abuse (physical and/or emotional).

older) are presented in Table 3. Participants who were less than 16 at the time of their MSM sexual debut were younger at the age of their heterosexual debut $(p=0.0001)$; younger when they received their HIV seropositive diagnosis $(p=0.02)$; and reported less education $(p<0.0001)$ compared to participants who had MSM sexual debut at age 16 or later. Overall, while participants with a MSM sexual debut less than 16 years of age were younger, this age difference was not large enough to account for the difference in education. There were no significant differences regarding site, race/ethnicity, selfreported sexual orientation, and current employment.

In terms of associated risk factors and emotional distress, being younger than 16 at the time of MSM sexual debut was significantly associated with engaging in exchange sex (past 3 months) (17\% vs. 10\%, $p=0.03)$ and drug use (past 3 months) (83\% vs. $65 \%, p=0.001)$, specifically marijuana use (70\% vs. $53 \%, p=0.003)$. Participants younger than 16 at the time of their MSM sexual debut reported more emotional/psychological problems from using drugs and/or alcohol (past 3 months) (21\% vs. $13 \%, p=0.05)$ and suicide attempts (29\% vs. $18 \%, p=0.02)$ compared to participants with a MSM sexual debut at age 16 or older (Table 4). There were no significant differences regarding unprotected sex (past 3 months), alcohol use (past 2 weeks), other drug use (past 3 months) (i.e., cocaine, sedatives, amphetamines, painkillers, inhalants, LSD, and heroin), and depressive symptomology (CES-D > 16; past 3 months).
Table 3. Characteristics by Age at MSM Sexual Debut for a Multisite Cohort of Racial/Ethnic Minority YMSM LIVING WITH HIV $(N=342)$

\begin{tabular}{|c|c|c|c|}
\hline \multicolumn{4}{|c|}{ Age at MSM sexual debut } \\
\hline & $\begin{array}{l}\text { Less than } \\
\text { age } 16 \\
(\mathrm{~N}=184)\end{array}$ & $\begin{array}{c}\text { Equal to } \\
\text { or greater } \\
\text { than age } 16 \\
(\mathrm{~N}=158)\end{array}$ & $\mathrm{p}_{\text {Value }}^{\mathrm{p}}$ \\
\hline \multicolumn{4}{|l|}{ Age (Mean, SD) } \\
\hline Heterosexual debut & $13.4(3.1)$ & $14.9(1.9)$ & 0.0001 \\
\hline HIV diagnosis & $19.7(2.2)$ & $20.2(1.9)$ & 0.02 \\
\hline \multicolumn{4}{|l|}{ Site $(N, \%)$} \\
\hline Oakland, CA & $14(8)$ & $14(9)$ & 0.31 \\
\hline Bronx, NY & $34(19)$ & $23(15)$ & \\
\hline Houston TX & $25(14)$ & $22(14)$ & \\
\hline Los Angeles, CA & $30(16)$ & $24(15)$ & \\
\hline Rochester, NY & $6(3)$ & $0(0)$ & \\
\hline Chapel Hill, NC & $36(20)$ & $42(27)$ & \\
\hline Detroit, MI & $28(15)$ & $22(14)$ & \\
\hline Chicago, IL & $11(6)$ & $11(7)$ & \\
\hline \multicolumn{4}{|l|}{ Race/ethnicity (N, \%) } \\
\hline African-American & $119(65)$ & $113(72)$ & 0.34 \\
\hline Latino & $41(22)$ & $26(16)$ & \\
\hline Multiracial $^{\mathrm{a}}$ & $24(13)$ & $19(12)$ & \\
\hline \multicolumn{4}{|l|}{ Sexual orientation $(N, \%)$} \\
\hline Gay/homosexual & $120(65)$ & $102(65)$ & 0.80 \\
\hline Bisexual & $35(19)$ & $34(21)$ & \\
\hline Heterosexual & $4(2)$ & $1(1)$ & \\
\hline Other $^{\mathrm{b}}$ & $25(14)$ & $21(13)$ & \\
\hline \multicolumn{4}{|l|}{ Education $(N, \%)$} \\
\hline $\begin{array}{l}\text { Less than high } \\
\text { school degree }\end{array}$ & $73(40)$ & $25(16)$ & $<0.0001$ \\
\hline $\begin{array}{l}\text { High school } \\
\text { degree/GED }\end{array}$ & $41(22)$ & $51(32)$ & \\
\hline Some college & $70(38)$ & $82(52)$ & \\
\hline Currently employed $(N, \%)$ & $82(46)$ & $70(45)$ & 0.94 \\
\hline
\end{tabular}

${ }^{\mathrm{a}}$ Multiracial $=$ African-American and Caucasian, African-American and Latino, African-American and Native American, and 3 or more race/ethnicities; ${ }^{b}$ Other $=$ two-spirited, bi-special, queer, trisexual, multiple identities, I'm me, and God's child.

\section{Discussion}

This study is the first to investigate risk factors associated with age at MSM sexual debut for racial/ethnic minority YMSM living with HIV. The findings partially support our hypothesis, with participants who had a MSM sexual debut before the age of 16 reporting more drug use (specifically marijuana); more emotional/psychological problems related to substance use; and more suicide attempts compared to participants with a later MSM sexual debut. While there was no reported difference in unprotected sex between participants who experienced an early or later MSM sexual debut, participants who had an early MSM sexual debut were more likely to report recent exchange sex. Sex is often exchanged to meet the basic needs (food and shelter) and/or for drugs. These type of exchanges places these youth at risk of transmitting their HIV to others. There is also the possibility of the acquisition of other STDs by these young men that contributes to overall poor health outcomes for themselves. Participants with a MSM sexual debut younger than age 16 were 
Table 4. Risk Factors by Age at MSM Sexual Debut for a Multisite COHORT of Racial/Ethnic MinORITY YMSM Living WITH HIV

\begin{tabular}{|c|c|c|c|}
\hline \multicolumn{4}{|c|}{ Age at MSM sexual debut } \\
\hline & $\begin{array}{l}\text { Less } \\
\text { than } \\
\text { age } 16\end{array}$ & $\begin{array}{l}\text { Equal to } \\
\text { or greater } \\
\text { than age } 16\end{array}$ & $\underset{\text { Value }}{\mathrm{p}}$ \\
\hline \multicolumn{4}{|c|}{ Sexual behavior without a condom, past 3 months $(N, \%)$} \\
\hline Insertive oral sex & $79(64)$ & $69(72)$ & 0.27 \\
\hline Receptive oral sex & $83(67)$ & $63(67)$ & 0.95 \\
\hline Insertive anal sex & $25(29)$ & $21(24)$ & 0.52 \\
\hline Receptive anal sex & $46(33)$ & $32(28)$ & 0.54 \\
\hline Vaginal sex & $5(43)$ & $0(0)$ & 0.20 \\
\hline Anal sex with women & $1(33)$ & $0(0)$ & 0.99 \\
\hline $\begin{array}{c}\text { Exchange sex }{ }^{\mathrm{a}} \text {, past } \\
3 \text { months }(N, \%)\end{array}$ & $32(17)$ & $15(10)$ & 0.03 \\
\hline $\begin{array}{c}\text { Drank alcohol, past } \\
2 \text { week }(N, \%)\end{array}$ & $66(49)$ & $52(46)$ & 0.57 \\
\hline \multicolumn{4}{|c|}{ Used drugs, past 3 months $(N, \%)$} \\
\hline Any drugs & $115(83)$ & $78(65)$ & 0.001 \\
\hline Marijuana & $100(70)$ & $65(53)$ & 0.003 \\
\hline Cocaine & $12(11)$ & $11(11)$ & 0.99 \\
\hline Sedatives & $15(14)$ & $12(12)$ & 0.63 \\
\hline Amphetamines & $16(15)$ & $10(10)$ & 0.29 \\
\hline Painkillers & $25(22)$ & $14(14)$ & 0.15 \\
\hline Inhalants & $13(13)$ & $9(9)$ & 0.45 \\
\hline LSD & $9(9)$ & $8(8)$ & 0.85 \\
\hline Heroin & $1(1)$ & $0(0)$ & 0.99 \\
\hline $\begin{array}{l}\text { Emotional/psychological } \\
\text { problems from using } \\
\text { drugs or alcohol, past } \\
3 \text { months }(N, \%)\end{array}$ & $37(21)$ & $19(13)$ & 0.05 \\
\hline \multicolumn{4}{|l|}{ CES-D $(N, \%)$} \\
\hline$<16$ & $77(46)$ & $75(49)$ & 0.64 \\
\hline$\geq 16$ & $89(54)$ & $78(51)$ & \\
\hline $\begin{array}{l}\text { Period of at least a week } \\
\text { of feeling sad, blue, } \\
\text { and unhappy, past } \\
3 \text { months }(N, \%)\end{array}$ & $40(55)$ & $33(60)$ & 0.56 \\
\hline Tried to take own life $(N, \%)$ & $50(29)$ & $27(18)$ & 0.02 \\
\hline
\end{tabular}

${ }^{a}$ Exchange sex = money, food, housing, drugs, transportation, and avoidance of abuse (physical and/or emotional).

also younger when they received their HIV seropositive diagnosis and had lower educational attainment. Understanding the age of onset of sexual behaviors as well as the context in which they occur is important for directing preventive interventions, particularly since such behaviors may be important correlates of risky sexual behavior (i.e., infrequent condom use) in addition to carrying risk for HIV and STDs. ${ }^{28}$ Both knowledge and skill-based interventions addressing the needs of these youth must be comprehensive and multifaceted. Such interventions also need to be implemented early, preferably prior to sexual debut, to impact the behaviors that place them at greatest risk for HIV acquisition.

Understanding initial sexual experiences among racial/ ethnic minority YMSM may provide researchers can provide some insight into the formation of high-risk behavior patterns. Additional qualitative data regarding the context in which these sexual experiences occurred (e.g., coercion, exchange sex) as well as information regarding partners (e.g., age, relationship status) could add to the richness of the narrative and be important for future interventions aiming to assist these young men in developing healthier sexual behaviors and relationships. Much remains to be learned about the circumstances of first intercourse. A comprehensive understanding of sex and sexual health may be lacking for many YMSM at the time of their sexual debut. This may be especially true for racial/ethnic minority YMSM who tend to experience an early sexual debut $^{29}$ (although it is noted that the average age of sexual debut for racial/ethnic minority YMSM in this study was similar to that of other youth in the US). Limited information about sex and sexual health at the time of their sexual debut may lead to unpleasant sexual experiences, as well as lack of confidence and skills to engage in safer sexual activities. ${ }^{29}$

Many YMSM report that their initial sexual experiences occurred with older adult men, bringing into question the voluntary nature of these experiences. ${ }^{13,30}$ In the current study, $19 \%(n=64)$ of the participants reported their MSM sexual debut at 13 years of age or younger. The legal age for sexual consent varies in our country, but no state currently has a law allowing legal sexual consent before the age of 13 , hence issues regarding the ability of these young men to consent to engage in sexual intercourse are of concern. Sexual abuse (whether acknowledged or not) may more accurately characterize the sexual debuts of many racial/ethnic minority YMSM (this sample included), and thus, the presence of childhood sexual abuse (CSA) should be explored when using initial sexual experiences to conceptualize, develop, and implement interventions for this population.

Previous studies in the US have found that the prevalence of CSA (ranging from $20 \%$ to $35 \%$ ) among MSM is significantly higher than among the general male population (ranging from $5 \%$ to $10 \%){ }^{31,32}$ Moreover, prevalence of CSA among racial/ ethnic minority MSM is higher than among White MSM. ${ }^{33,34}$ A predictive relationship between CSA, high-risk sexual behavior, and increased HIV prevalence among MSM has been shown, ${ }^{31,32,34-40}$ although this relationship is mediated by multiple variables (e.g., partner type, substance use during sex). CSA has also been associated with depressive symptoms, feelings of isolation, substance abuse, and suicidality. ${ }^{34,39-41}$ Thus, providers caring for racial/ethnic minority YMSM living with HIV should inquire about possible CSA and initial sexual experiences to be able to provide comprehensive care and to attempt to reduce continued engagement in risk behavior. CSA among men like women is often under-reported and undertreated. Moreover, interventions that attempt to impact highrisk sexual behaviors that place this population at risk for HIV should seriously consider the inclusion of a detailed account of initial sexual experiences (context and partners) with a particular focus on those that report a sexual debut before age 16. Such interventions should also focus on activities that will help these young men build healthy relationships. Finally, any intervention for this population must be racially/ethnically sensitive in order to address culturally relevant issues and concerns that characterize the lives racial/ethnic minority YMSM.

\section{Limitations}

This study has some limitations. First, participants in this study were a convenience sample of racial/ethnic minority 
YMSM living with HIV who were being linked to care. Thus, they may not be representative of all racial/ethnic minority YMSM living with HIV (i.e., youth living with HIV who are not linked to care). Additionally, detailed information was not obtained about the initial sexual experiences of the participants (i.e., context and partners). This information is valuable to characterize the nature of initial sexual experiences (i.e., consensual sex versus sexual abuse), as well as possible HIV transmission, since the odds of HIV infection have been found to increase significantly as the age of sexual partner increases. $^{42,43}$ Future studies should include a comprehensive detailed assessment of initial sexual experiences. Moreover, information regarding exchange sex is needed to determine the exact nature of the behaviors (e.g., initial sexual experiences, older partners, condoms used with partners) and how it contributes to the overall level of sexual risk for this population. Also, only baseline data was utilized for analyses, and therefore causality could not be inferred. Finally, it is also noted because there was no comparison group of HIV-negative racial/ethnic minority YMSM, it cannot be determined if these data are unique HIV-positive racial/ethnic minority YMSM.

\section{Conclusions}

The current study contributes to the literature on sexual initiation for racial/ethnic minority YMSM, including the engagement in risk behaviors and levels of emotional distress. This is the first study to investigate risk factors associated with age at sexual debut for racial/ethnic minority YMSM living with HIV. Additional research is needed to assist in the development of comprehensive interventions that can be implemented prior to sexual debut. This subpopulation of youth appears to have some unique characteristics (e.g., racial/ethnic minorities, same gender relationships, early sexual debuts) that may be challenging for prevention efforts. Therefore, interventions that are specifically designed for racial/ethnic minority YMSM (i.e., culturally sensitive and relevant) and emphasize comprehensive sexual health education and healthy relationships at a young age when their sexual identity is developing (i.e., sex education and condom negotiation), may assist with reducing risk behaviors and factors for this population.

\section{Author Disclosure Statement}

No competing financial interests exist.

\section{References}

1. Centers for Disease Control and Prevention. HIV and AIDS among gay and bisexual men. CDC Fact Sheet 2010: Atlanta, GA: U.S. Department of Health and Human Services.

2. Centers for Disease Control and Prevention. HIV testing among racial/ethnic minorities United States, 1999. MMWR Morb Mortal Wkly Rep 2001;50:1054-1058.

3. MacKellar DA, Valleroy LA, Secura GM, et al. Unrecognized HIV infection, risk behaviors, and perceptions of risk among young men who have sex with men: Opportunities for advancing HIV prevention in the third decade of HIV/AIDS. J Acquir Immune Defic Syndr 2005;38:603-614.

4. Valleroy LA, MacKellar DA, Karon JM, et al. HIV prevalence and associated risks in young men who have sex with men. JAMA 2000;284:198-204.
5. Millett GA, Flores SA, Peterson JL, et al. Explaining disparities in HIV infection among black and white men who have sex with men: A meta-analysis of HIV risk behaviors. AIDS 2007; 21:2083-2091.

6. Millett GA, Peterson JL, Wolitski RJ, et al. Greater risk for HIV infection of black men who have sex with men. A review of critical literature. Amer J Public Health 2006;96: 1007-1019.

7. Harawa NT, Greenland S, Bingham TA, et al. Associations of race/ethnicity with HIV prevalence and HIV-related behaviors among young men who have sex with men in 7 urban centers in the United States. J Acquir Immune Defic Syndr 2004;35:526-536.

8. Kolbin BA, Husnik MJ, Colfax G, et al. Risk factors for HIV infections among men who have sex with men. AIDS 2006;20:731-739.

9. Hein K, Dell R, Futterman D, et al. Comparison of HIV+ and HIV- adolescents: Risk factors and psychosocial determinants. Pediatrics 1995;95:96-104.

10. Murphy DA, Durako SJ, Moscicki AB, et al. No change in high-risk behavior over time among HIV-infected adolescents in care: Role of psychological distress. J Adolesc Health 2001;29:57-63.

11. Rotheram-Borus MJ, Murphy DA, Coleman CL, et al. Risk acts, health care, and medical adherence among HIV youths in care over time. AIDS Behav 1997;1:43-52.

12. Tanney MR, Naar-King S, Murphy DA, et al. Multiple risk behaviors among youth living with human immunodeficiency virus in five U.S. cities. J Adolesc Health 2010;46:11-16.

13. Elkington KS, Bauermeister JA, Zimmerman MA. Psychological distress, substance use, and HIV/STI risk behaviors among youth. J Youth Adolesc 2010;39:514-527.

14. Stein J A, Rotheram-Borus, MJ, Swendeman D, et al. Predictors of sexual transmission risk behaviors among HIVpositive young men. AIDS Care 2005;17:433-442.

15. Naar-King S, Wright K, Parsons, J, et al. Transtheoretical Model and condom use in HIV+ youth. Health Psych 2006;25:648-652.

16. Edwards JM, Iritani BJ, Hallfors DD. Prevalence and correlates of exchanging sex for drugs or money among adolescents in the United States. Sex Transm Infect 2006;82:354-358.

17. Roy E, Haley N, Leclerc P, et al. Prevalence of HIV infection and risk behaviours among Montreal street youth. Int J STD AIDS 2000;11:241-247.

18. Cavazos-Rehg PA, Krauss MJ, Spitznagel EL, et al. Age of sexual debut among US adolescents. Contraception 2009;80:158-162.

19. Eaton DK, Kann L, Kinchen S, et al. Youth risk behavior surveillance-United States, 2007. MMWR Morb Mortal Wkly Rep 2008;57:1-131.

20. Grunbaum JA, Kann L, Kinchen SA, et al. Youth risk behavior surveillance-United States, 2001. J Sch Health 2002;72:313-328.

21. Finer LB. Trends in premarital sex in the United States, 1954-2003. Public Health Rep 2007;122:73-78.

22. Abma J, Driscoll A, Moore K. Young women's degree of control over first intercourse: An exploratory analysis. Fam Plan Perspect 1998;30:12-18.

23. Roosa MW, Tein JY, Reinholtz C, et al. The relationship of childhood sexual abuse to teenage pregnancy. J Marriage Fam 1997;59:119-130.

24. Stock JL, Bell MA, Boyer DK, et al. Adolescent pregnancy and sexual risk-taking among sexually abused girls. Fam Plan Perspect 1997;29:200-203, 227. 
25. Albert B, Brown S, Flanigan C. (Eds.). 14 and Younger: The Sexual Behavior of Young Adolescents. Washington DC: National Campaign to Prevent Teen Pregnancy; 2003.

26. Lohman, B J, Billings A. Protective and risk factors associated with adolescent boys' early sexual debut and risky sexual behaviors. J Youth Adolescent 2008;37:723-735.

27. Radloff LS. The CES-D scale: A self report depression scale for research in the general population. App Psyché Maes 1977;1:385-401.

28. Ompad DC, Strathdee SA, Celentano DD, et al. Predictors of early initiation of vaginal and oral sex among urban young adults in Baltimore, Maryland. Arch Sex Behav 2006;35:53-65.

29. Kubrick K, Beyer W J, Weiss G, et al. In the dark: Young men's stories of sexual initiation in the absence of relevant sexual health information. Health Ed Behav 2010;37:243-263.

30. Catania JA, Paul J, Osmond D, et al. Mediators of childhood sexual abuse and high-risk sex among men-who-have-sexwith-men. Child Abuse Nell 2008;32:925-940.

31. Lenderking WR, Wold C, Mayer KH, et al. Childhood sexual abuse among homosexual men. Prevalence and association with unsafe sex. J Gen Intern Med 1997;12:250-253.

32. Paul JP, Catania J, Pollack L, et al. Understanding childhood sexual abuse as a predictor of sexual risk-taking among men who have sex with men: The Urban Men's Health Study. Child Abuse Negl 2001;25:557-584.

33. Arreola SW, Neilands, TB, Pollack LM, et al. Higher prevalence of childhood sexual abuse among Latino men who have sex with men than non-Latino men who have sex with me: Data from the Urban Men's Health Study. Child Abuse Negl 2005;29:285-290.

34. Fields SD, Malebranche D, Feist-Price S. Childhood sexual abuse in black men who have sex with men: Results from three qualitative studies. Cultur Divers Ethnic Minor Psychol 2008;14:385-390.

35. DiIorio C, Hartwell T, Hansen N. Childhood sexual abuse and risk behaviors among men at high risk for HIV infection. Am J Public Health 2002;92:214-219.

36. Jinich S, Paul JP, Stall R. Childhood sexual abuse and HIV risk-taking behavior among gay and bisexual men. AIDS Behav 1998;2:41-51.
37. Mimiaga MJ, Noonan E, Donnell D. Childhood sexual abuse is highly associated with HIV risk-taking behavior and infection among MSM in the EXPLORE study. J Acquir Immune Defic Syndr 2009;51:340-348.

38. O'Leary A, Purcell D, Remien RH, et al. Childhood sexual abuse and sexual transmission risk behaviour among HIVpositive men who have sex with men. AIDS Care 2003;15: 17-26.

39. Purcell DW, Malow RM, Dolezal C, et al. Sexual abuse of boys: Short- and long- term associations and implications for HIV prevention. In: Koenig LJ, O'Leary A, Pequegnat W, eds. From Child Sexual Abuse to Adult Sexual Risk: Trauma, Revictimization, and Intervention. Washington, DC: American Psychological Association 2004: 93-114.

40. Stall R, Mills TC, Williamson J, et al. Association of co-occurring psychosocial health problems and increased vulnerability to HIV/AIDS among urban men who have sex with men. Am J Public Health 2003;93:939-942.

41. Bartholow BN, Doll LS, Joy D, et al. Emotional, behavioral, and HIV risks associated with sexual abuse among adult homosexual and bisexual men. Child Abuse Negl 1994;18: 747-761.

42. Hurt CB, Matthews DD, Calabria MS, et al. Sex with older partners is associated with primary HIV infection among men who have sex with men in North Carolina. J Acquir Immune Defic Syndr 2010;54:185-190.

43. Bingham TA, Harawa NT, Johnson DF, et al. The effect of partner characteristics on HIV infection among African American men who have sex with men in the Young Men's Survey, Los Angeles, 1999-2000. AIDS Educ Prev 2003;15: 39-52.

Address correspondence to: Angulique Y. Outlaw, Ph.D. Wayne State University School of Medicine 4201 St. Antoine

UHC, 6 E. 29

Detroit, MI 48201

E-mail: aoutlaw@med.wayne.edu 

Copyright of AIDS Patient Care \& STDs is the property of Mary Ann Liebert, Inc. and its content may not be copied or emailed to multiple sites or posted to a listserv without the copyright holder's express written permission. However, users may print, download, or email articles for individual use. 